\title{
Solar Heat in Industrial Processes in Switzerland - Theoretical Potential and Promising Sectors
}

\author{
Martin Guillaume ${ }^{1}$, Mircea Bunea', Marco Caflisch², Mercedes H. Rittmann-Frank², José Martin ${ }^{3}$ \\ ${ }^{1}$ Laboratory of Solar Energetics and Building Physics (LESBAT), HES-SO/HEIG-VD, Route de \\ Cheseaux 1, CH-1401 Yverdon-les-Bains (Switzerland) \\ 2 Institut für Solartechnik SPF, Hochschule für Technik HSR, Oberseestrasse 10, CH-8640 \\ Rapperswil-Jona (Switzerland) \\ ${ }^{3}$ Swissolar, Neugasse 6, CH-8005 Zürich (Switzerland)
}

\begin{abstract}
The aim of this work is to identify the potential of conventional solar systems for industrial process heating and determine the most suitable Swiss industrial sectors for its implementation. For this purpose, a detailed study of the Swiss industry energy consumption is carried out in order to obtain the amount of thermal energy consumed by process heating. Subsequently, this amount of energy is analysed for each industrial sector and those for which the energy demand could be provided by conventional solar thermal systems are sorted out. The theoretical potential for conventional solar thermal systems in the Swiss industry is therefore, estimated taking into account the most promising industrial sectors revealing an important implementation potential. Finally, the study also assese the potential for the implementation of solar process heat systems for different regions and cantons in Switzerland.
\end{abstract}

Keywords: Solar thermal collectors, industrial process heating, potential, Switzerland

\section{Introduction}

According to the International Energy Agency (IEA), the final energy consumption in the world reached 9384 Mtoe, equivalent to $392.8 \mathrm{EJ}$, in 2015 . In the same year, the industry sector represented nearly $30 \%$ of this worldwide energy consumption, with fossil fuels being the main energy vector (International Energy Agency (IEA), 2018). The IEA balance sheet shows that electricity represented only $27 \%$ of the industry energy consumption while fossil fuels, which include oils, coal and natural gas, represented $61 \%$.

In Switzerland, the final energy consumption represented $855 \mathrm{PJ}$ in 2016 for which the industry sector accounted for 18\% during the same year (Swiss Federal Office of Energy, 2017). The largest part of the energy consumed by the industry is used directly in process heating applications. Integration of solar thermal (ST) systems as energy source for industrial processes is a research area that has seen a growing interest last decade. According to Horta (2017), around $30 \%$ of the total industrial heat demand is required at temperatures below $150{ }^{\circ} \mathrm{C}$ and could theoretically be met with conventional solar thermal technologies, such as flat-plate and evacuated tube collector.

Some ST systems have been set up in Switzerland to supply process heating applications in different industrial sectors such as in dairy products manufacturing, machinery products manufacturing or bitumen production (Bunea et al., 2017). Some of them use conventional solar thermal system such as that used to heat the pretreatment washbasins of coating device (Rittmann-frank et al., 2017). A large spectrum of industrial processes can benefit from the integration of solar thermal technologies and important energy savings can occur as well as greenhouse gas reductions but the potential of this type of system is so far largely unexploited.

In this work, only the potential of conventional solar thermal systems for process heating is studied, including flat plate collectors and evacuated tube collectors. These systems have proven their efficiency and reliability in the residential sector. As these systems provide efficiently heat up to $130^{\circ} \mathrm{C}$, only the share of heat consumption for process heating with operating temperatures in this range is consided here. Industrial sectors having a large share 
of heat demand for process heating occurring at low temperature are therefore selected as promising sectors for the implementation of conventional ST systems and the theoretical potential is calculated for these sectors.

\section{Methodology}

In order to identify the potential of conventional ST systems for industrial process heating in Switzerland, a detailed analysis of the energy consumption of the Swiss industry was performed considering separately the total energy consumption (electricity and heat) and the thermal energy consumption (heat only). Data on industry energy consumption was obtained from the Swiss Overall Energy Statistics GEST, established by the Swiss Federal Office of Energy (SFOE) and corresponding to the year 2016.

The GEST calculation respects the territory principle and only takes into account the energy consumed inside the Swiss territory in the form of an energy balance sheet presenting and detailing the gross energy consumption and the final energy consumption. All data on energy consumption presented here corresponds to the final energy consumption as provided by Swiss Federal Office of Energy (2017). With these data it is possible to differentiate final consumption between thermal and electrical energy. Another advantage is the possibility to identify the energy vectors from which the final consumption of thermal energy is issued. Finally, it is possible to identify the final energy consumption of the Swiss industry sector and its distribution by energy vector

Industry sectors have been defined according to the NOGA 2008 classification, used by the Swiss Federal Office of Statistics (SFOS) and the SFOE, which groups the Swiss companies in 88 economic divisions, including 37 for the industry. For this study, these economic divisions of the industry are grouped into 12 sectors to facilitate the analysis. These 12 industrial sectors have been defined according to the SFOS and are identical to the classification structure used in the study of Swiss Federal Office of Energy (2012).

The SFOS, through its database STAT-TAB (Swiss Federal Office of Statistic, 2017), allows obtaining different statistics about the industry in Switzerland. In this study, the distribution of the industrial sectors is used to identify the cantons where industry energy consumption is largest. The variable chosen for this distribution is the full time equivalent (FTE) employment which leads to the energy consumption by canton for each industrial sector.

\section{Swiss Industry Energy Consumption}

In 2016, industry sector consumed around 155PJ, accounting for $18 \%$ of the total Swiss final energy consumption (see Figure 1). The industry electricity consumption accounted for only $7 \%$ of the total energy consumption in Switzerland and $30 \%$ of the total Swiss electricity consumption.. Regarding the industry heat consumption, it accounted for $11 \%$ of the total energy consumption in Switzerland and represented $14 \%$ of the total heat consumption in Switzerland.

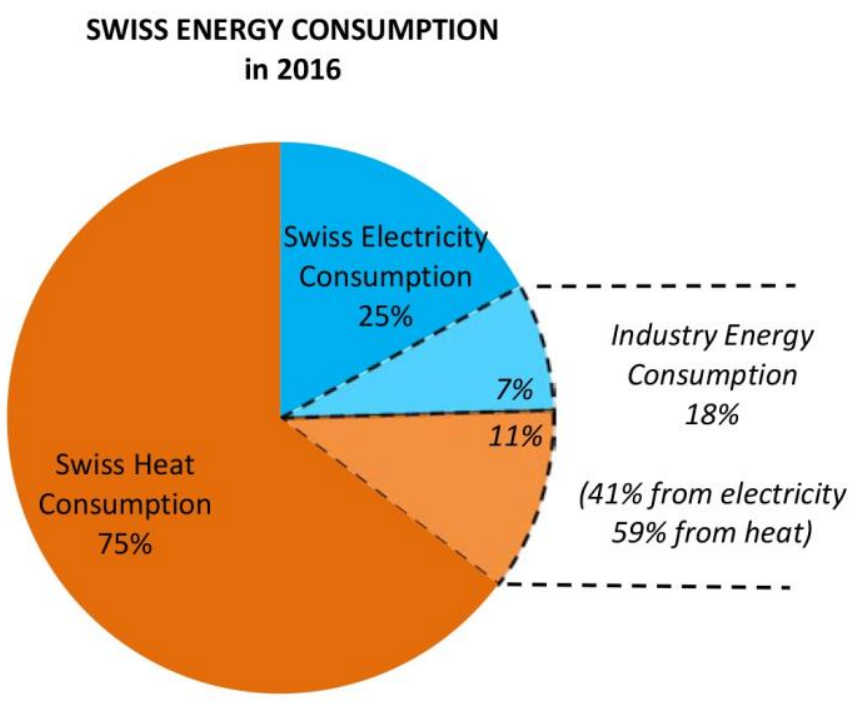

Fig. 1: Swiss energy consumption and share of the industry (own calculation based on Swiss Federal Office of Energy (2017)) 
The share of heat consumption in relation to the total energy consumption of the industry represented $59 \%$, whereas it represented $41 \%$ in the case of electricity consumption, in 2016. This distribution shows that heat consumption is more important than electricity consumption, but the latter still accounts for a large part of the energy consumption of the industry sector in Switzerland.

Various energy vectors provide the heat consumed by the industry. Fossil fuels accounted for about $66 \%$ of the industry thermal energy consumption. The part of renewable energies (RE), wood and others renewables energies, represented $14 \%$ of the industry heat consumption which is still much lower than the part of fossil fuels. There is still a high potential for solar thermal systems to replace the high share of fossils fuels used in the energy mix.

Energy-intensive industries represent a great potential for integrating solar thermal systems as energy source to improve RE share and avoid fossil fuels utilisation. To identify the Swiss major energy consuming industries, the energy consumption shares of each industrial sectors are presented as a percentage of the total industrial sector energy consumption and the corresponding percentages in terms of industry thermal demand, in 2016 (see Figure 2).

\section{INDUSTRY TOTAL ENERGY CONSUMPTION by INDUSTRIAL SECTOR in 2016}
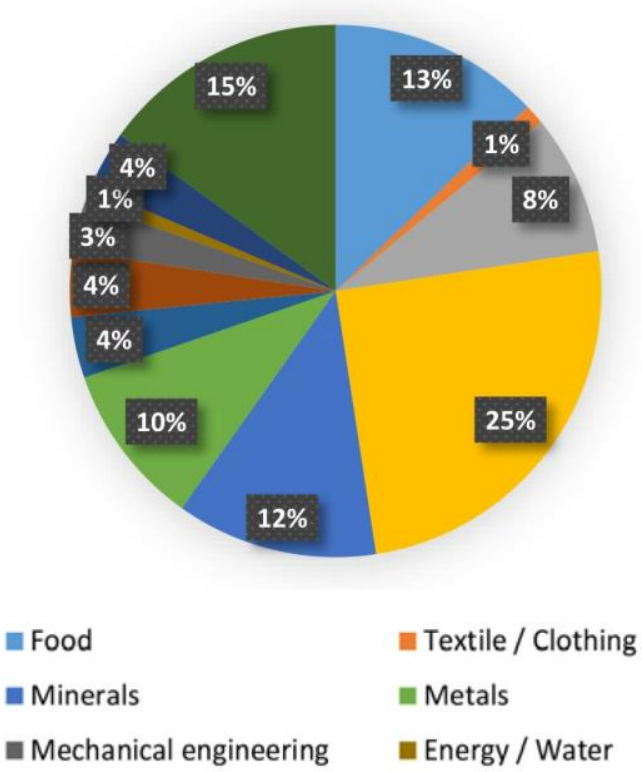

\section{INDUSTRY THERMAL ENERGY CONSUMPTION by INDUSTRIAL SECTOR in 2016}

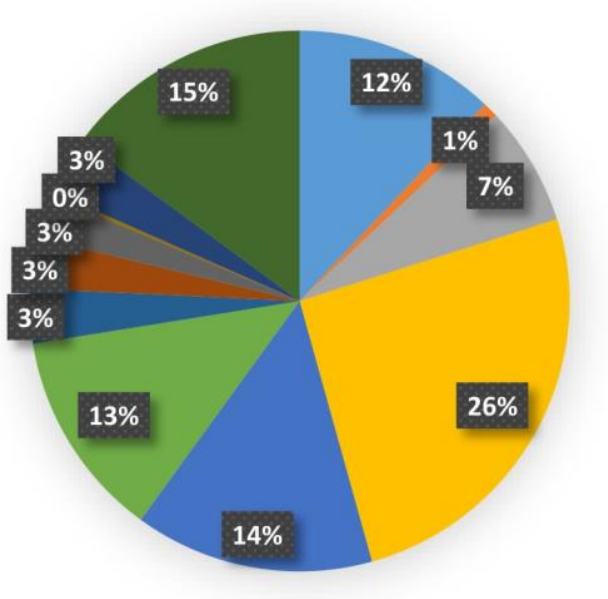

$$
\begin{aligned}
& \text { - Paper } \\
& \text { Metal products } \\
& \text { - Construction }
\end{aligned}
$$

“ Chemistry / Pharma

Electrical engineering

ather industry

Fig. 2: Energy consumption shares of industry sectors in 2016 (own calculation based on Kemmler et al. (2017))

Among the different industry sectors, the largest consumer is the chemistry/pharma sector, followed by food, minerals, metals and paper industries. All these equate to about $68 \%$ of the industry total energy consumption and for $72 \%$ of the industry thermal energy consumption in 2016.

In 2016, the amount of energy consumed by the chemistry/pharma sector reached $39 \mathrm{PJ}$, accounting for $25 \%$ of the industry total energy consumption. The thermal energy consumed by this sector reached $23 \mathrm{PJ}_{\mathrm{th}}$, representing $26 \%$ of the industry thermal energy consumption.

The second largest industrial energy consumer in Switzerland, accounting for $13 \%$ of the industry total energy consumption in 2016, is the food sector, which includes manufacturing food, beverages and tobacco. The energy consumption for this sector is as follows: $54 \%$ for heat and $46 \%$ for electricity. The heat consumption of the food industry reached $11 \mathrm{PJ}_{\text {th }}$ in 2016 , which represented $12 \%$ of the industry thermal energy consumption.

Other energy-intensive industries are those of the minerals sector, which includes non-metallic mineral products other than rubber and plastic products such as cement or ceramic industries. This is followed by the metals industry, which includes industries of smelting and refining ferrous and non-ferrous metals, and finally the paper industry, which includes the manufacture of pulp, paper and converted paper products. These three industrial sectors represent respectively $12 \%, 10 \%$ and $8 \%$ of the industry total energy consumption, and $14 \%, 13 \%$ and $7 \%$ of the industry thermal energy consumption. 
The Other industry category is not considered because it includes different industries that are not bound, adding extra difficulties in to the energy consumption behaviour analyse. Nevertheless, it accounts for a large amount of the industry energy consumption in 2016 , representing $15 \%$ of the industry total energy consumption and $15 \%$ of the industry thermal energy consumption.

This analysis has highlighted the industries that accounted for most of the Swiss industry energy consumption. The five industrial sectors, mentioned above, represented together almost three-quarter of the industry thermal energy consumption. Overall, the industrial sector breakdown of total energy consumption (electricity and heat) and thermal energy consumption (heat only) are nearly identical. This means that industrial sectors with large energy consumption have large heat demand.

\section{Industrial Process Heat Consumption}

\subsection{Industry Energy Consumption by Application}

To understand energy usage within the different industrial processes and how solar thermal systems could be potentially implemented, the evaluation of the process heat demand is performed. Kemmler et al. (2017) provides the distribution of the industry energy consumption by application and compares the share of heat and electricity consumption for each application. Figure 3 shows the total energy consumed by each application and the share of electricity and heat consumption compared to the industry total energy consumption, for 2016.

APPLICATION ENERGY CONSUMPTION

by ENERGY VECTOR in 2016

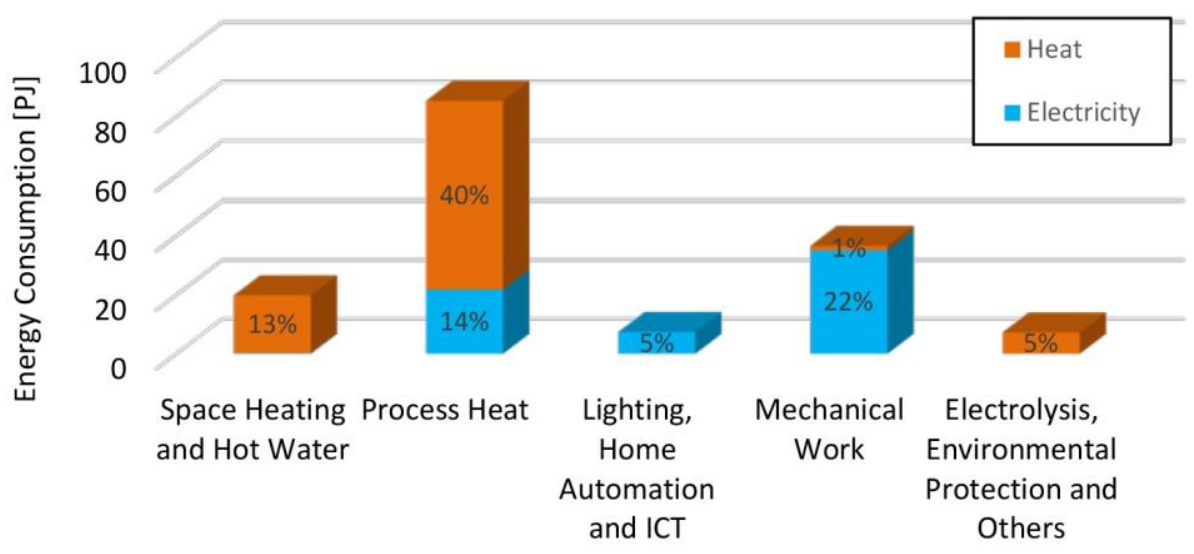

Fig. 3: Industrial application energy consumption by energy source in 2016 (own calculation based on Kemmler et al. (2017))

The amount of energy consumption for hot water, space heating and process heat applications is mostly provided by thermal energy whereas lighting, home automation, ICT (Information and Communication Technologies) and mechanical work applications is almost totally provided by electricity. The last group of applications, regrouping electrolysis, environmental protection and others processes is also totally provided by thermal energy. However, this last category will not be considered in this study because it includes processes for which no information is available. Consequently, mechanical work and lighting, home automation and ICT were not considered as potentially suitable to ST systems implementation because their demand is essentially in electricity.

Because the purpose of this study is the integration of ST systems in process heat, hot water and space heating applications are excluded in the analysis of the potential of solar thermal systems in Swiss industry, but they still represent interesting applications. Indeed, all the energy consumed by these applications is in the form of thermal energy and accounts for $13 \%$ of the industry total energy consumption. In addition, the suitability of these applications to benefit from solar is even larger because the thermal demand occurs at temperatures below $60^{\circ} \mathrm{C}$.

In terms of industrial energy consumption, it can be seen that process heating is the largest energy consumer in the industry sector. This application consumed 85 PJ during the year 2016, representing 54\% of the total energy consumption of the Swiss industry. A closer look into industrial process heating, shows that the share of energy consumed by process heat application is $75 \%$ from heat and $25 \%$ from electricity. Electricity demand for process 
heating is excluded from this study because it will involve consistent changes in the heat distribution system (additional hydraulic pipes, pumps, heat exchangers, etc.) raising considerably the global cost of the system and implicitly reduce the financial performance of the global system. Nevertheless, in some cases, electric heaters could also be effectively replaced by solar thermal systems.

For all these reasons, only the potential of solar thermal systems to provide the thermal energy consumption for process heating is considered in this work. This amount of energy represented $40 \%$ of the industry energy consumption in 2016.

\title{
INDUSTRY THERMAL ENERGY CONSUMPTION by APPLICATION in 2016
}

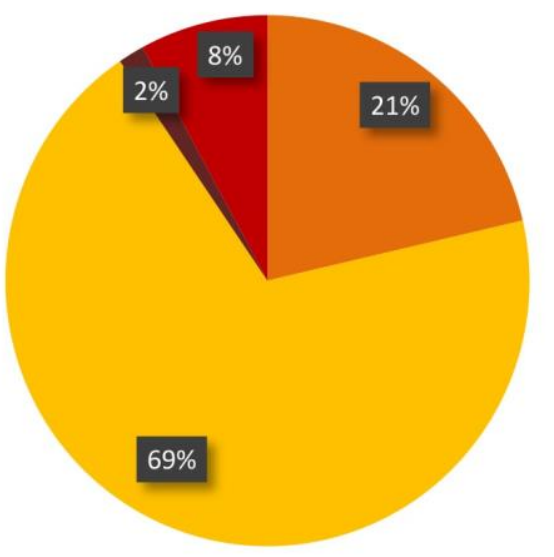

\author{
Space Heating and Hot \\ Water \\ Process Heat \\ Mechanical Work \\ Electrolysis, \\ Environmental \\ Protection and Others
}

Fig. 4: Industry energy consumption by application in 2016 (own calculation based on Kemmler et al. (2017))

As shows in the industrial application breakdown of Swiss thermal energy consumption (Figure 4), process heating is the largest consumer. The heat demand for this application reached $63 \mathrm{PJ}_{\mathrm{th}}$, representing $69 \%$ of the industry thermal energy consumption in 2016, thus more than two-thirds. As demonstrated above, this amount of energy is mostly provided by fossil fuels. It therefore represents a great potential for renewable energies, such as ST, to reduce the greenhouse gas emissions of the Swiss industry.

\subsection{Process Heat Consumption by Industrial Sector}

To identify the promising industrial sectors where integration of ST systems may have a significant impact on the reduction of fossils fuels consumption, the distribution of the thermal energy consumption for process heating by industrial sector is displayed in Figure 5.

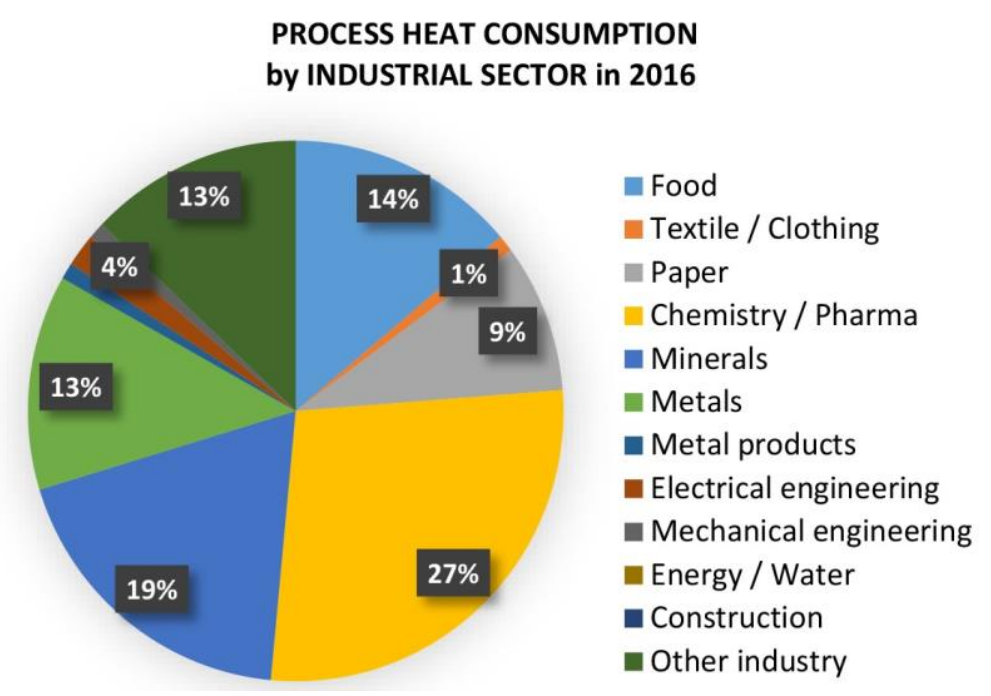

Fig. 5: Thermal energy consumption for process heat application by industrial sector in 2016 (own calculation based on Kemmler et al. (2017) and on Swiss Federal Office of Energy (2017)) 
The chemistry/pharma industry, which is the highest energy consumer sector in terms of total energy consumption (see Figure 2), is also the sector with the largest part of thermal energy use for process heating. The amount of thermal energy consumed for this purpose reached $18 \mathrm{PJ}_{\mathrm{th}}$ for this sector, accounting for $27 \%$ of the thermal energy consumption for this application. The second largest consumer of thermal energy for industrial process heating in Switzerland, accounting for $19 \%$, is the minerals industrial sector, where the amount of thermal energy consumed for this purpose, in 2016, reached $12 \mathrm{PJ}_{\mathrm{th}}$. The thermal energy consumption for process heat reached $9 \mathrm{PJ}_{\mathrm{th}}$ for the food industry sector, representing $14 \%$ of the thermal energy consumption use for this application. In the case of the metals sector, the amount of energy consumed for this purpose reached $8 \mathrm{PJ}_{\text {th }}$, representing $13 \%$ of the thermal energy consumption used for this application in the Swiss industry. Another high thermal energy consumer sector is the paper sector, where the amount of thermal energy consumed for process heat reached $6 \mathrm{PJ}_{\text {th }}$ in 2016 , representing $9 \%$ of the industry thermal energy consumption used for process heating.

Others industrial sectors do not account a lot in the thermal energy consumption used for process heating in the Swiss industry. The textile/clothing sector represented $1 \%$ with less than $1 \mathrm{PJ}_{\mathrm{th}}$ consumed. The electrical, mechanical, energy/water and construction sector represented together $4 \%$ in 2016 . As mentioned previously, the Other industry category groups various industrial sectors and is not considered in this study. Nevertheless, this category account for a large part of the thermal energy consumed for process heat in 2016, representing $13 \%$.

Regarding only the thermal energy consumption for process heating in 2016, the distribution trend between the different industrial sectors appears to be similar to the thermal energy consumption distribution considering all applications. As shown previously, this is because process heating is the higher thermal energy consuming application in the Swiss industry, so that industrial sectors, having a large part of heat process applications, consume more than the others.

Promising sectors for implementation of ST systems are those that have process heating application representing a large part of their thermal energy consumption. Figure 6 presents the distribution of thermal energy consumption by application for each industrial sector.

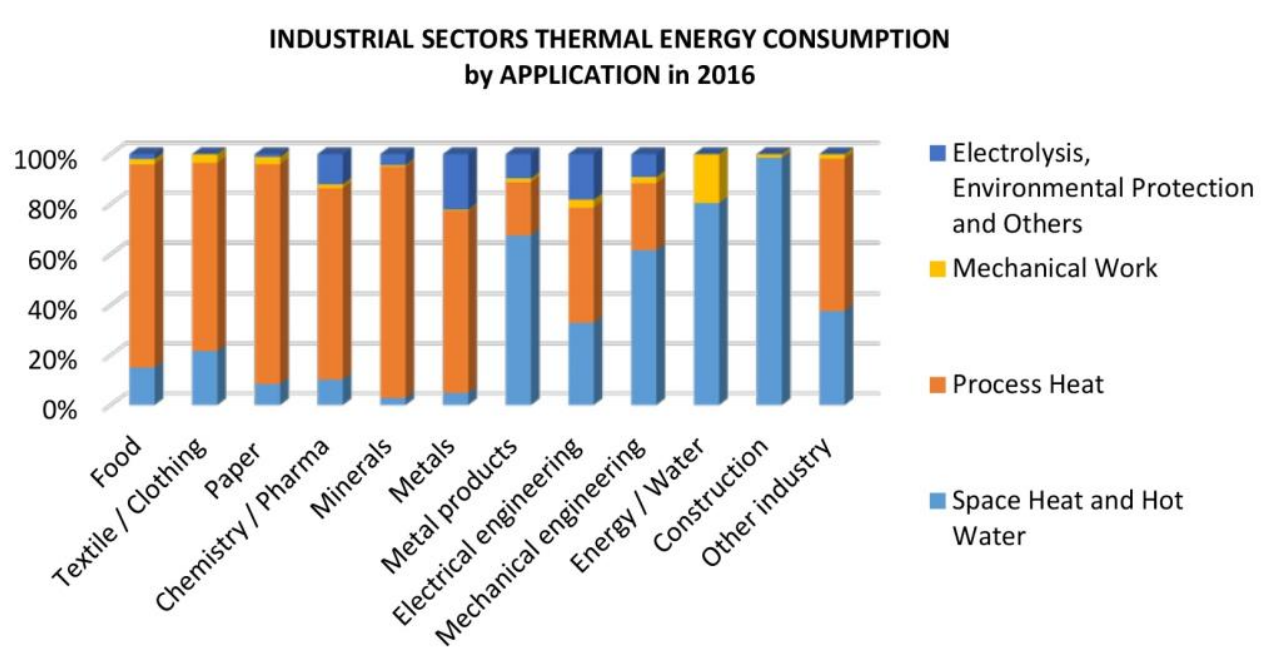

Fig. 6: Thermal energy consumption distribution by application for each industrial sectors in 2016 (own calculation based on Kemmler et al. (2017) and on Swiss Federal Office of Energy (2017))

The industrial sectors representing the largest share of thermal energy consumption in Switzerland in 2016, are also those that have a high thermal energy consumption in process heating. Therefore, these are the more interesting sectors to consider for solar thermal systems implementation. These sectors are the food sector, the paper sector, the chemistry/pharma sector, the minerals sector and the metals sector where process heating application represented respectively $81 \%, 88 \%, 76 \%, 92 \%$ and $73 \%$ of their thermal energy consumption.

For the five industrial sectors mentioned above, representing the largest consumers of thermal energy, the share of energy consumption for process heating represents an important part of their heat demand. Therefore, these industrials sectors are pre-selected as potentially suitable for implementation of solar thermal systems in process heating applications. The textile/clothing sector despite its small part in the industry thermal energy consumption is also pre-selected due to the share of its heat consumption for process heating, representing $75 \%$. 
The amount of heat consumption for process heating in these six sectors reaches $53 \mathrm{PJ}_{\text {th }}$ in 2016 , representing $57 \%$ of the industry thermal energy consumption and 33\%, thus a third, of the industry total energy consumption (electricity and heat).

\section{Solar Heat Potential for Industrial Processes}

\subsection{Promising Industrial Sectors}

Heat demand for process heating occurs at different temperature levels depending on the industry sector. In order to determinate the real potential of conventional solar systems in the pre-selected industrial sectors, it is necessary to identify the temperature level at which the heat processes occur. To our knowledge, no studies are available on the distribution of the heat demand according to the temperature level for the Swiss industry. However, there are many studies dealing with this subject in Europe and abroad. Since, there is no study on the specific distribution of the heat delivery by temperature range for Switzerland, this distribution is assumed to be similar to that of other European countries.

Distribution of the heat demand by temperature range is obtained from the data of the European study (Pardo et al., 2012). This study provides the distribution of the heat demand by temperature range for different industrial sectors in the EU-27 countries. The definition of industrial sectors considered in the latter is almost the same that those used in the present study. The only difference is the paper industry sector, which also includes the printing sector in the European study.

The distribution of the industry heat demand is divided into three temperature levels. The low temperature range (LT) corresponds to temperatures below $100^{\circ} \mathrm{C}$ and is the temperature range required for conventional solar system applications. The medium temperature range (MT) corresponds to temperatures between $100^{\circ} \mathrm{C}$ and $400^{\circ} \mathrm{C}$. The high temperature range $(\mathrm{HT})$ corresponds to temperatures higher than $400^{\circ} \mathrm{C}$.

Figure 7 presents the distribution of the heat demand for the pre-selected industrial sectors according to the three temperature levels.

INDUSTRY HEAT CONSUMPTION in EU-27

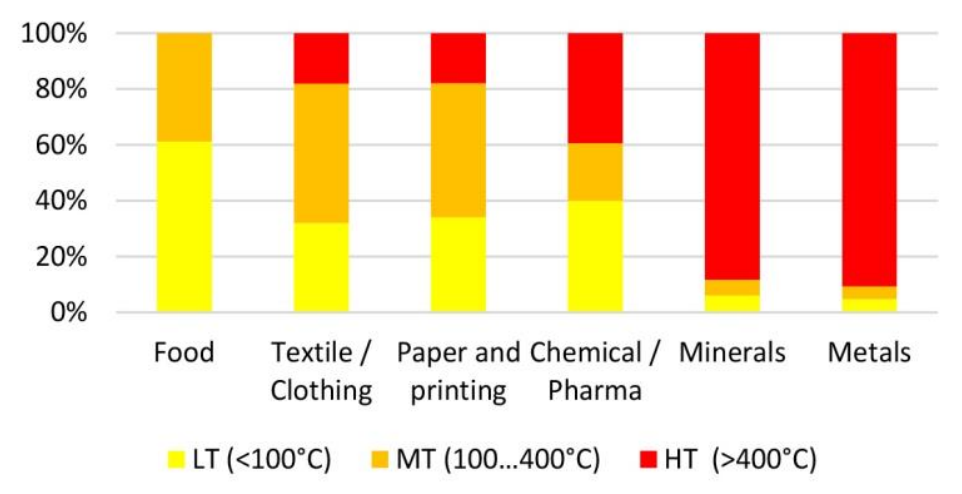

Fig. 7: Distribution of the industry heat demand by temperature level in EU-27 (own calculation based on Pardo et al. (2012))

Significant differences between the heat consumption behaviour of the pre-selected industry sectors can be observed. The food sector has heat consumption only at low and medium temperature ranges. Textile/clothing and paper sectors have more than $80 \%$ of their heat demand at these same temperature ranges. The chemical/pharma sector also has its largest part of heat demand occurring at low and medium temperature ranges. As this study focuses on low temperature ranges $\left(<130^{\circ} \mathrm{C}\right)$ for the implementation of conventional solar thermal systems, it clearly appears that the more promising sectors are:

- food

- textile/clothing

- paper

- chemical/pharma 
The share of heat consumption in the low temperature range for these industrial sectors represents a minimum of $30 \%$, reaching more than $60 \%$ in the case of the food industry (percent of total heat demand for process heating).

In the minerals and metals sectors some process heating occurs at low temperatures, e.g. pickling; metal surface treatment; mineral cleaning, but the largest part of their heat demand is at high temperatures. For this reason, they are not considered as promising industry sectors for the implementation of conventional ST collectors.

The food industry sector, which includes manufacturing of food products, beverages and tobacco products, appears to present an important potential for solar technology. According to the Euroheat \& Power study (Werner and Constantinescu, 2006), more than half of the heat demand for its processes is in the low temperature range with the remaining in the medium temperature range. As far as this study is concerned, it appears that almost $61 \%$ of the heat demand for process heating falls into the low temperature range.

The textile/clothing industry sector includes the manufacturing of textiles, wearing apparel and leather and related products. It appears that this industry has $32 \%$ of its thermal energy consumption at low temperature ranges and almost $50 \%$ at medium temperature ranges.

The paper sector includes the manufacturing of paper and paper products. According to Lauterbach (2014), twothirds of the heat demand in the paper sector is at temperatures below $200^{\circ} \mathrm{C}$. Concerning heat demand at temperature below $100^{\circ} \mathrm{C}$, its share represents $34 \%$, almost as for the textile/clothing industry.

The chemical/pharma sector includes the manufacturing of chemicals and chemical products, basics pharmaceutical products and pharmaceutical preparations. This is an extremely important sector because, it accounts for a large part of the Swiss industry thermal energy demand as already demonstrated in Figure 2 within the Swiss industrial context. According to Pardo et al. (2012) the share of thermal energy consumption used for process heating at temperatures below $100^{\circ} \mathrm{C}$ represents $40 \%$.

\subsection{Theoretical Potential in Swiss Industry}

The amount of thermal energy consumed by the four industrial sectors selected, presenting the greatest potential for conventional solar thermal systems, reached $41.4 \mathrm{PJ}_{\text {th }}$ in 2016 . This accounts for $26 \%$ of the industry total energy consumption (electricity and heat) and $46 \%$ of the industry thermal energy consumption. As far as process heating is concerned, the amount of energy consumed by these four industrial sectors represented $33 \mathrm{PJ}$ th, which accounted for $35 \%$ of the industry thermal energy consumption.

The theoretical potential for conventional thermal solar systems depends on the share of low temperature heat demand of each industrial sector. As explained in the Pardo et al (2012) study, the LT range includes the heat demand for process heating and also the heat demand for space heating $(\mathrm{SH})$ and hot water $(\mathrm{HW})$. In the context of this study, these applications are excluded in the analysis of the potential of ST systems. Then the amount of energy consumed by these applications is excluded in the final theoretical potential.

To identify this theoretical potential, the total amount of thermal energy consumed for process heating, hot water and space heating applications by each selected industrial was calculated. The share of heat demand occurring at low temperature is identified using the share of LT from the Pardo et al (2012) study. Finally, the theoretical potential for ST system for LT process heating application is calculated by subtracting the heat demand for space heating and hot water applications. Table 1 presents the theoretical potential for each selected industrial sector.

Tab. 1: Theoretical potential at low temperature operation for each industrial sector

\begin{tabular}{|c|c|c|c|c|c|}
\hline \multirow[b]{2}{*}{ Industrial Sector } & \multicolumn{2}{|c|}{$\begin{array}{c}\text { Thermal Energy } \\
\text { Consumption }\end{array}$} & \multirow{2}{*}{$\begin{array}{l}\text { Low Temperature } \\
\text { Demand }\left(<100^{\circ} \mathrm{C}\right)\end{array}$} & \multirow{2}{*}{$\begin{array}{c}\text { Low } \\
\text { Temperature } \\
\text { Heat Demand } \\
{[\mathrm{PJ}]}\end{array}$} & \multirow{2}{*}{$\begin{array}{c}\text { Theoretical } \\
\text { Potential } \\
\text { [PJ] }\end{array}$} \\
\hline & $\begin{array}{c}\text { SH and HW } \\
\text { [PJ] }\end{array}$ & $\begin{array}{c}\text { Process } \\
\text { Heating } \\
\text { [PJ] }\end{array}$ & & & \\
\hline \multirow{4}{*}{$\begin{array}{c}\text { Food } \\
\text { Textile/Clothing } \\
\text { Paper } \\
\text { Chemistry/Pharma }\end{array}$} & 1.6 & 8.8 & $61 \%$ & 6.3 & 4.7 \\
\hline & 0.2 & 0.6 & $32 \%$ & 0.3 & 0.1 \\
\hline & 0.5 & 5.7 & $34 \%$ & 2.1 & 1.6 \\
\hline & 2.3 & 17.7 & $40 \%$ & 8.0 & 5.7 \\
\hline
\end{tabular}


The theoretical potential for conventional thermal solar system in these four industrial sectors accounts for 12.1PJ. This represents $13 \%$ of the industry thermal energy consumption and $8 \%$ of the industry total energy consumption (electricity and heat) during the year 2016. This value represents the estimation of thermal energy used for process heating that would be entirely provided by conventional solar thermal systems.

This theoretical potential for conventional solar thermal systems to provide heat in industrial processes is equivalent to more than 8 Million $\mathrm{m}^{2}$ installed ST collectors considering an annual yield of $400 \mathrm{kWh} / \mathrm{m}^{2}$. However, to estimate the real technical potential is necessary to take into account more consideration such as available space for systems installation, profile load of the processes energy consumption, energy storage opportunities, etc...

In the context of this study, it was chosen to identify the specific potential of solar thermal systems for process heating. However, the potential for these systems is more important considering that they can equally provide energy for hot water production, space heating and also to replace part of the electricity used for process heating. In this case, the theoretical potential for the selected industrial sectors represents 16.7PJ, equivalent to $10 \%$ of the industrial total energy consumption. Considering all the industrial sectors, the thermal energy consumption for hot water production and space heating reached $18 \mathrm{PJ}$ in 2016, then the theoretical for conventional ST system is even greater.

The electricity consumption of industrial process heating, which represented 22 PJ in 2016 for all Swiss industry, could also been of interest for the potential of solar thermal systems. Indeed, depending on the temperature requirements, the heat could be provided by conventional solar thermal systems and replace the use of electricity.

This shows that the real potential for conventional solar systems is greater than highlighted in this study. Moreover, as the conventional solar systems can provide heat up to $130^{\circ} \mathrm{C}$, it can be added the heat requirement that occurs at temperature between $100^{\circ} \mathrm{C}$ and $130^{\circ} \mathrm{C}$. Nonetheless, this energy consumption is not considered in this study because of the lack of data on the proportion of industrial processes taking place at this temperature range.

More recent developments as the concentrating technologies or the ultra-high vacuum fat plate collectors could also cover temperatures ranges up to $400^{\circ} \mathrm{C}$ efficiently and could contribute to a considerable raise of the energy delivered to the industrial process heat. Nevertheless, this range is not taken into account because these technologies are often more difficult to install and are more costly. Therefore, the potential announced above represents only the heat that could be covered by ST collectors easily and at a competitive price compared to the actual price of fossil fuels.

This result together with data from the distribution of these sectors across Switzerland (Swiss Federal Office of Statistic, 2017), makes it is possible to obtain the potential of each canton for the implementation of conventional solar thermal systems for process heating. Figure 8 shows the distribution of the theoretical potential, considering the four selected industrial sectors by canton.

THEORETICAL POTENTIAL FOR CONVENTIONAL SOLAR THERMAL SYSTEM by CANTON

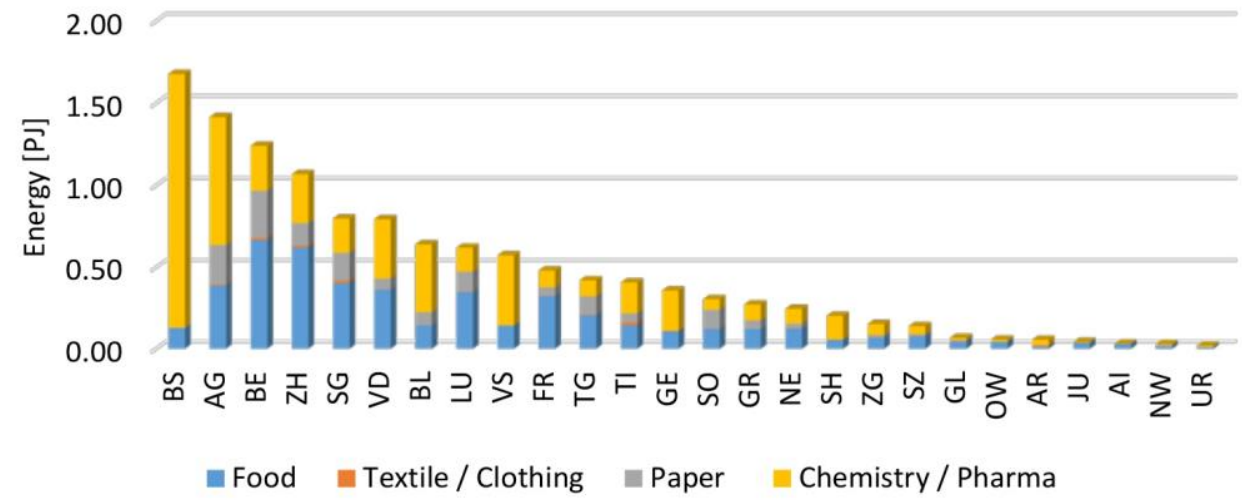

Fig. 8: Potential for conventional thermal solar systems for heat process in Switzerland (own calculation based on Swiss Federal Office of Statistic (2017)) 
The canton of Basel-City is where the theoretical potential is most important with an amount greater than 1.7PJ. It follows the canton of Aargau with a potential of 1.4PJ. The cantons of Bern, Zurich, St. Gallen and Vaud present a potential of $1.2 \mathrm{PJ}, 1.1 \mathrm{PJ}, 0.8 \mathrm{PJ}$ and $0.8 \mathrm{PJ}$, respectively.

\section{Conclusion}

A deep screening of the Swiss energy consumption was made in this work with a focus on the industry sector. The heat demand is carefully analysed depending on the industrial sector, energy vector, application and temperature level. Because of the Swiss organisation with different specifications for each canton, a geographical classification of the energy industrial demand was also carried out in order to highlight the potential of ST systems in each canton.

According to the Swiss Overall Energy Statistics GEST, the Swiss industry consumed 156 PJ in the year 2016, accounting for $18 \%$ of the final energy consumption in Switzerland. The main energy-consuming application in the industry resulted to be process heating. This application consumed 85PJ. The share energy demand for this application supplied by electricity was not taken into account in this study reducing the investigated energy consumption to $63 \mathrm{PJ}$ or about $40 \%$ of the Swiss industry energy demand.

Food, textile and clothing, paper, chemistry and pharma sectors are interesting for solar thermal systems implementation because they have a high thermal energy consumption in process heating and a high share of low operating temperature. These four industrial sectors have together an amount of heat demand for process heating reaching 33PJ, which accounted for $21 \%$ of the Swiss industry energy consumption in 2016.

Out of this demand, the share of heat demand for process heating application that occurs at low temperature $\left(<100^{\circ} \mathrm{C}\right)$ is estimated at $12.1 \mathrm{PJ}$ representing the theoretical potential for conventional thermal solar system in these four industrial sectors. This value represents $8 \%$ of the final energy consumption made by the Swiss industry during the year 2016 and $1.4 \%$ of total energy consumption in Switzerland. Several assumptions have been made in this work in order to identify processes where ST could easily replace fossil fuels. Therefore, it is important to mention that the theoretical potential energy supplied by ST conventional technologies can considerably increase with taking into account all industry sectors, other applications than process heat (e.g. space heat and HW) or the part of process heat supplied by electricity. Furthermore, processes occurring at higher temperature levels, up to $400^{\circ} \mathrm{C}$ could also be partly covered by different ST technologies such as concentrating or the ultra-high vacuum fat plate collectors.

This study highlights the important potential of conventional ST technologies to cover low temperature process heat in the Swiss Industry. It indicates the most favorable industrial sectors for ST implementation, the most suitable processes and also the regions where it is more likely to install such systems. Therefore it provides basic elements for different actors (industrials, ST manufacturers, planners/installers and policy makers) in order to help them increase energy efficiency in this sector and implicitly reduce greenhouse gas emissions which will greatly contribute to meet the targets of the Swiss Energy Strategy 2050. 


\section{References}

Bunea, M., Eicher, S., Bony, J., Duret, A., Citherlet, S., 2017. Medium Temperature Solar Thermal Installation for Industrial Thermal Storage of Bituminous Products, in: Proceedings of SWC2017/SHC2017. International Solar Energy Society, Freiburg, Germany, pp. 1-10. https://doi.org/10.18086/swc.2017.26.01

Horta, P., 2017. Solar Heat for Industrial Processes - Available Technologies, Design Procedures, Upcoming Innovations.

International Energy Agency (IEA), 2018. Energy Balance Flows 2015 [WWW Document]. URL http://www.iea.org/Sankey/

Kemmler, A., Koziel, S., Wüthrich, P., Benedikt, N., Keller, M., Martin, J., Catenazzi, G., 2017. Analyse des schweizerischen Energieverbrauchs 2000 - 2016 nach Verwendungszwecken, Bundesamt für Energie. Bern, Switzerland.

Lauterbach, C., 2014. Potential, system analysis and preliminary design of low-temperature solar process heat systems. Kassel Univ. Press. Kassel University.

Pardo, N., Vatopoulos, K., Krook-Riekkola, A., Moya, J.A., Perez, A., 2012. Heat and cooling demand and market perspective. Publications Office of the European Union. https://doi.org/10.2790/56532

Rittmann-frank, M.H., Möllenkamp, J., Caflisch, M., Häberle, A., 2017. Evaluation of Solar Process Heat projects in Switzerland Potential for Solar Process Heat in Switzerland, in: Proceedings of SolarPaces2017.

Swiss Federal Office of Energy, 2017. Schweizerische Gesamtenergiestatistik 2016 Statistique globale suisse de l'énergie 2016, Bundesamt für Energie. Bern, Switzerland.

Swiss Federal Office of Energy, 2012. Die Energieperspektiven für die Schweiz bis 2050, Bundesamt für Energie. Basel, Switzerland.

Swiss Federal Office of Statistic, 2017. STAT-TAB [WWW Document]. URL https://www.pxweb.bfs.admin.ch

Werner, S., Constantinescu, N., 2006. EcoHeatCool WP1: The European heat market, Euroheat \& Power. Brussels, Belgium. 